\title{
Responding to Climate Change and the Role of Environmental law
}

\author{
Assoc. Prof. Dr. Vu Thị Duyen Thuy \\ Hanoi Law University, Vietnam
}

Doi:10.19044/elp.v8no3a1

URL:http://dx.doi.org/10.19044/elp.v8no3a1

Submitted: 02 August 2021

Accepted: 17 September 2021

Published: 30 September 2021
Copyright 2021 Author(s)

Under Creative Commons BY-NC-ND

4.0 OPEN ACCES

\begin{abstract}
:
Climate change has been putting humankind at risk with a host of challenges regarding the aspects of environment and development. More specifically, it requires excessive effort from all countries, in which recognizing the importance of environmental law system plays an indispensable role. Therefore, in this article, the role of environmental law in tackling climate change will be analyzed and, based on the provided analysis, solutions on building and improving the environmental law for more efficient implementation will be laid out to lessen the adverse effects of climate change.
\end{abstract}

Key Words: Climate change, environmental law, environment.

\section{Introduction}

According to the Article 1 of the United Nations Framework Convention on Climate Change in 1992, climate change is defined as the harmful effects caused by the change of the global climate. In details, the changes in physical and biological environments directly lead to significant threats to not only the compositions of the environment, the abilities to recover and reproduce of the natural eco-system but also the activities to develop socio-economic aspects as well as the health and benefits of humankind (UN,1992). The stated change is made by both direct and indirect impacts from man-made activities and the fluctuations of weather observed during the periods that alter the compositions of the global atmosphere. The main cause of climate change can be considered as the escalation in the number of man-made activities that discharge greenhouse gas and the excessive exploitation of greenhouse gas sinks ranging from biomass, forests to marine, coastal and terrestrial eco-systems. Several figures indicating climate change include the rising sea levels in coastal areas, the resulting land loss, ocean warming, the fluctuations in temperature of sea surface, storms, floods, etc (Fahim, 2021). including:

In terms of environmental protection, climate change has caused many alarming challenges

Firstly, increasing the risk of forest degradation.

When the heat of the Earth rises, the temperature and the amount of evaporation increases correspondingly, which heightens the possibilities of forest wildfire. This is counted as an environmental incident that reduces severely the number and the quality of forest resources on a wide scale. Besides, the rise of the sea level also proposes serious threats to the well-being of the Mangrove and Melaleuca forest eco-system, which is seen as one of the specialties of the wetlands. Aside from that, due to the influence of climate change, the frequency and intensity of floods and storms increase, which leads to the severe degradation of many types of eco-system including the 
forest one. Furthermore, the risk of degradation of biological diversity has become foreseeable since the loss of habitat has caused the reduction in numbers of animals and plants as well as the destruction of forest ecosystem.

Secondly, increasing the risk to the water resources.

Under the adverse impact of climate change, as the average temperature rises, the fluctuation of climate, weather, and natural catastrophes also proposes significant threats to the water resources, especially during the period that the demand for water in daily life, in agricultural manufacture, in the industries, energy, and traffic gradually increases. Meanwhile, evaporation in waterbodies such as ponds, lakes, streams, etc. faces a sharp rise and, with the changes in rain, the currents of rivers, the density of floods, and the characteristics as well as the rising frequency of drought are negatively altered. Besides, the melting of ices in both Earth's poles and mountain peaks also contribute substantially to the stronger stream flows and more frequent floods. When the ices on tops of the mountains start to be depleted, the appearance of floods will be lessened but the resulting decrease of stream flows likely lead to severe shortage of water. Climate change proposes direct impacts on the whole hydrologic cycle, in which the rise in temperature is predicted as the changer of annual and seasonal rainfall patterns, of groundwater levels and the moisture of both soil and snow. Besides, it also influences the changes in river flows, raises the sea levels as well as the evaporation and transpiration rates. As a result, the outcomes may vary among different places but the state of water shortage, floods, lower-quality water, coastal erosion, and salinization are probable (VACNE, 2009; EC, 2015).

Thirdly, increasing the risk to the land resources.

Under the adverse impact of climate change, especially with the higher sea level, the residence of the local inhabitants and the areas of fertile land for agricultural production will be narrowed. In fact, natural disasters, storms, floods happening more often will lead to the erosions of not only land but also riverbanks and the coasts as well as the leaching and sedimentation of the beds, which are considered harmful to the land resources. Therefore, water shortages and droughts, as the results of the stated situation, likely cause desertification (Nguyen Duc Ngu, 2008).

Fourthly, increasing the risk of the degradation of biological diversity.

The rise of the Earth's heat has put many creatures in nature at the risk of massive reduction in numbers and, in a more extreme condition, extinction. The main causes are thought to be the contraction of living habitats of natural species, desertification, forest destruction, and warmer oceans, in which many types of animals and plants fail to timely adapt to such drastic changes (Walter, 2010). Besides, changes in climatic conditions and the amount of carbon dioxide happen in a faster pace leading to significant impacts on the ecosystem. Influenced by the heat, air, and the melting of ices, the number of barrier reefs is facing decreasing tendency. This means that terrestrial and marine ecosystems are both bearing the effects of floods, droughts, forest wildfire, and the oceanic acidization. Meanwhile, the rise of sea level also harms the well-being of the hydrology. As a result, the existing biomes are under changes in compositions and the additional reserves are possibly reduced (Vo Quy, 2009). In the $21^{\text {st }}$ century and beyond, the risk of extinction that terrestrial and aquatic species might face will be escalating in all possible scenarios. It should be noted that the changes in the ecosystem are more relevant to climate changes. More specifically, mass extinction is caused by various factors but climate change is seen as one with predictable future escalation (Canadian, 2015).

\section{The role of environmental law in dealing with climate change}

First of all, the activities to adapt and lessen the impacts of climate change are considered as the main way for humankind to respond to this issue (Vietnam, 2014). Theses activities can be initiated by many different actors with distinctive methods. In order to guarantee the efficiency in 
implementation of those activities for better adaptation and lesser effects from climate change, the role of the government is seen as indispensable. By different means, the government is able to foreplan, operate, and bind the relevant actors to launch the stated activities and environmental law is an effective tool for such purpose. As the main driver being capable of adjusting the social network, the law system always has substantial influence on the social network itself, which can be shown on different degrees depending on the specific targets and connections for further law adjustments (HLU, 2015; Nguyen Minh Doan, 2008).

Within the law system of most of the countries in the world, environmental law was conducted later than many other types (HLU, 2016). In fact, environmental law system is built and realized for the purposes of not only assuring the freshness of the environment, protecting the natural resources, but also minimizing the risks to the well-being of humankind and the environment. In other words, environmental law contains regulations on protecting the quality as well as the compositions of the environment, lessening the damage to the environment in general, and mitigating the adverse effects of climate change in particular.

Following the purposes of adapting and lessening the effects of climate change, the regulations within the environmental law frequently propose changes in several basic issues such as on managing harms to the ozone layers; managing greenhouse gas; eco-friendly production and consumption; using recyclable energy sources. These rules help cope with the incurring social connections during the implementation of activities related to the environmental compositions regarding the purpose of restricting emissions; preventing and mitigating the negative impacts to the environment in general and the atmosphere in particular; protecting the living habitats for humankind. By steering the behaviors of the governmental agencies and organizations as well as individuals with specific system of sanctions, environmental law not only show to all related actors the way to adapt to climate change during implementation but also prevent the potential causes of climate change as well. In order to achieve this goal, the laws in many countries have considered the responses to climate changes as a vital institution. This situation can be adjusted through either the Law on Climate Change Prevention or the regulations stated in the Law on Environmental Protection as well as the by-laws per se. This justifies the role of environmental laws in dealing with climate change, especially in the following terms:

Firstly, environmental law is an effective tool to prevent and limit the risk of aggravating the ongoing damage of climate change.

In the modern era, facing the pressure of economic development and the existing impacts of climate change being much visible, the importance of ensuring the quality of the living environment for humankind and lessening the possibilities of a more severe influence caused by climate change are becoming undeniable yet extremely challenging. Environmental Law, including regulations on responding to climate change, plays an indispensable part as the main tool of management. In fact, it creates frameworks on behavioral principles, in which the targeted actors are obliged to comply during implementation of environment-related activities with necessary measurement of sanctions. For instance, when initiating activities that come with emissions of greenhouse gas and other harmful components for the ozone layers, organizations and individuals are responsible for obeying the behavioral guidance within the rules to reduce emission, to prevent pollutions and environmental accidents as well as to generate solutions and coping methods for the purpose of ensuring the general health of humankind. Besides, environmental law also regulates criminal, civil, and administrative sanctions to bind the organizations and individuals to the responsibilities of complete compliance vis-à-vis the legal requirements on climate change prevention. By applying the aforementioned sanctions, environmental law aims to not only punish the related misconduct but also to deter the possibilities of future ones that may escalate the situations of climate change.

Secondly, environmental law creates favorable conditions for the formations and developments of newly-found professions in responding to climate change. 
By approving the regulations on issues related to responses to climate change such as: the reduction of emissions of greenhouse gas, regulations on retrieving energy from wastes, policies to promote and assist the uses of recycled energy and eco-friendly appliances during production, etc., environmental law not only tackle the environmental pollution caused by productions and businesses but also foster their development to moderner technological paths with safety for implementation. The mentioned professions are created as the result of the requirements in responding to climate change with the formations and development of environmental industries in many countries as the most prominent example.

Environmental industry is newly-created and an inevitable response to the demand for sustainable development. This is seen as an economic industry that produce goods and services to protect the environment and to satisfy the needs of the national economy. This type of industry contains a wide range of products and services with diversity that solely focuses on processing harmful wastes, both in liquid and solid forms; on controlling air and noise pollutions. It also includes managing wastes, recycling technologies and the services of collecting wastes for recycling as well as retrieving energy from trash to limit the risks to the environment ( $\mathrm{Vu}$ Thi Duyen Thuy, 2016). More specifically, the essence of this industry is environmental serviceoriented and it is operated with efficiency in many countries such as Germany, France, China, etc. In those countries, environmental law has shown its effectiveness as the guarantee of indispensable legal conditions for the formations and development of environmental industry. In general, it contributes substantially to the higher efficacy of adaptation and the mitigation of climate change.

Thirdly, environmental law helps promote scientific research and applications of most up-todate technologies for the purpose of better adaptation and climate change mitigation.

In the responses to climate change, technologies are seen as an important element. By applying the most modern, fresh technologies with minimal amount of wastes discharged, human is able to eliminate greenhouse gas, harmful components for the ozone layers as well as the most basic causes of climate change. However, researching and applying these technologies are facing many obstacles, especially regarding the incompetence in technological capacities of the developing countries. In that scenario, the regulations of the environmental law will promote the applications and the research of modern technologies to the waste source owners in order to reduce the amount of harmful components that causes climate change. In fact, one of the management principles stated in this legal system forces the actors that discharge wastes to implement provided methods to limit the above components to the minimal levels. To do that, the waste source owners are obliged to research and apply appropriate technological processes of production as well as waste disposal processes. In addition, the uses of eco-friendly ones and recycled energy are also highly recommended. Furthermore, environmental law also creates favorable conditions for organizations and individuals in researching and applying modern technologies that help reduce wastes and ensure safety for the environment during implementation. This is normally shown through the concretization of preferential policies of the government on taxes, land, capitals, etc. These policies provide promotion and economic motivation for the organizations and individuals to research and apply the fresh, eco-friendly technological processes.

Fourthly, environmental law helps change and raise awareness as well as call for the responsibility of the community in responding to climate change.

Environmental law is responsible for guiding the community in terms of proper responsibility and behaviors that are beneficial to the environment per se. Through the specific rules, environmental law assists organizations and individuals in having thorough understanding and applications of suitable methods of exploitation of natural resources with minimal levels of harmful effects to nature (Joep, 1997). Besides, environmental law also rase the awareness of the consumers in using eco-friendly and healthy products. The requirements being gradually stricter environment-wise of the products consumed by global citizens, especially in developed countries where consumers have good understanding of environmental protection, are the clear and visible 
evidences that prove the utmost importance of environmental law. Moreover, any products that fail to deliver eco-friendliness and contain harmful risks to the environment during production or consumption will be boycotted. In logical terms, when the consumers start to prefer using ecofriendly products to their counterpart, the risks of aggravating climate change will be fully controlled.

Therefore, environmental law plays a crucial part in responding to climate change. It requires countries to adjust the awareness in environmental protection in general and in responding to climate change in particular. Hence, completing the legal system in this aspect is urgently called for in order to timely solve the major environmental challenges that climate change has brought to humankind.

\section{Suggestions}

Climate change is complex and its adverse impacts on nature and the lives of human are gradually aggravated. Thus, to promote the role of environmental law and to adapt as well as to mitigate climate change, environmental law needs to satisfy the following requirements:

Firstly: environment law must create favorable conditions for maximum mobilization of technical and financial sources to respond to climate change. In order to effectively perform this requirement, the regulations need to create favorable conditions for the investors who apply technologies to reduce wastes and to efficiently retrieve energy from wastes as well as to optimize recycled energy. Besides, regulations that promote and provide assistances to the above activities need to be enacted. Aside from that, preferential policies on tax for enterprises applying ecofriendly production and producing eco-friendly products; regulations about methods of assistance toward agencies retrieving energy from wastes and researching technological applications in responding to climate change are necessary to create economic boost for the organizations, individuals in future activities of climate change mitigation.

Secondly: environmental law must be the proper tool to assist the specialties of the above activities. In order to satisfy this requirement, behavioral rules provided within the regulations need to be reasonable, science-based, and understandable. These rules not only create favorable conditions for actors in environmental legal relations to deliver the requirements of responding to climate change, but also ensure the effectiveness of the regulations per se. These technical guidelines also need to be developed to meet this requirement. They are the necessary supplements with professional orientation for organizations and individuals as well as government agencies to respond to climate change.

Thirdly: environmental law must assure the management role of the State. With the strict technical requirements and the expenditures to respond to climate change, expectations in the selfsufficiency of organizations and individuals in performing safety requirements for the well-being of the environment and public health are difficult to meet. Therefore, the permanent management role of the State needs to be assured over these activities and, to do that, specific and consistent regulations on environmental law enforcement institutions in responding to climate change is mandatory. The activities to enforce regulations in responding to climate change and to coerce compliance of laws as well as the supervision over implementation of the government agencies also need to be adjusted with details in accordance to environmental law. Furthermore, there exists intertwined relations between the responsibilities of the State and human rights as well as the issues regarding climate change. Statistics and analyses have indicated that neither international human rights law nor international climate change law exclude the possibility of applying law regarding the responsibility of the State toward obligations in coping with climate change (Margaretha 2019). Therefore, clear specification on the responsibility of the State is considered as a vital task in tackling climate change. 
With the stated requirements, in order to ensure the consistency of the legal corridor for the activities responding to climate change, environmental law needs to regulate specifically the following points:

(i) Integrate the content of responding to climate change into the strategies of socioeconomic development. To ensure the capability in implementing the activities to adapt and mitigate climate change and the ones to perform economic and socio-cultural development simultaneously, the contents on responding to climate change need to be integrated into the strategies and plans of economic development as well as the related regulations. This is the result of the complexity and diversity of the impacts of climate change on the economy, society, and environment. Therefore, applying solutions separately without consistency is unlikely to produce any promising results since it calls for integration with activities on socio-economic development. This means that, in each phase of the aforementioned activities, adaptation and mitigation of climate change will be controlled and initiated consistently and appropriately to ensure both the objectives of enhancing socio-economic development and of reducing the risks of climate change caused by socio-economic development activities per se. Hence, integrating the responses to climate change within the strategies and consistent plans provided will create the chemistry for more efficient cooperation among all departments on all scales including between the locals and the regional management agencies as well as other locals.

(ii) Managing greenhouse gas emission and harmful components to the ozone layers. The main reason that caused climate change to the Earth is the increase in activities that emit greenhouse gas, over-exploitation in greenhouse gas sinks such as biomass, forests, marine, coastal, and land ecosystems. Hence, reducing the amount of emission of greenhouse gas and controlling the harmful components to the ozone layers are compulsory in order to ease the impacts of climate change. For the purpose of adjusting and fixing this situation, aside from enacting regulations on managing emission, assigning the responsibilities specifically to the related actors on managing greenhouse gas and harmful components to the ozone layers is necessary. On the other hand, regulations on incentives, aid to the activities that help minimize the amount of greenhouse gas and ones on clean development as well as production are also vital.

(iii) The development of recycled energy and the retrieval of energy from wastes. In fact, recycled energy is the type of energy that is exploited from water, wind, sunshine, geothermal heat, wave, biological fuel, and other renewable energy sources. These types of energy come from sources that are able to self-replenish and are impossible to be depleted. They are clean energy sources that not only cause no air pollution but also play no role in global warming nor greenhouse effects so taking advantage of them is beneficial for the purpose of mitigating climate change (Edmond, 2018). However, according to the statistics of World Bioenergy Association in 2020, fossil fuel is still maintaining its dominant position in the global energy sources, in which $81 \%$ of total primary energy supply includes production, import, export, bunkers is generated from coal, crude oil and natural gas. On the other hand, renewable energy technologies including solar, wind, hydroelectric, biomass and geothermal energy accounted for only $13.8 \%$ of primary energy supply in 2018 (WBA, 2020). According to that, in order to reduce climate change, it is necessary to promote programs on developing renewable energy on the basis of a consistent, unified legal framework.

Renewable energy technologies have been one of the most important strategies in addressing sustainable energy development and climate change. The roles of renewable energy in developing countries are vital, which include the accessibility of modern energy services in rural areas, climate change mitigation, energy security, green job creation and eventually improvement of quality of life (Hoyyen, 2018). With the development of renewable energy sources, retrieving energy from wastes is also an activity that needs to be encouraged to limit the risks of climate change. It not only effectively tackles the ongoing issues of environmental pollution and helps 
expand land but also contributes to solve the existing energy problems. Its importance and position among other efforts in responding to climate change are undeniable and, to realize it, the environmental law of most of the countries in the world all needs to be adjusted to encourage organizations and individuals to use recycled energy and to retrieve energy from wastes during implementation. Thus, producing, importing, using appliances and green vehicles or serving the purpose of the stated energy retrieval should all be exhorted. In fact, the environmental law of many countries in the world has already approached this tendency.

(iv) Producing and consuming eco-friendly products. Eco-friendly products are ones that meet the eco-label criteria and are certified as eco-label. Currently, global consumers are gradually seeking green and eco-friendly products and seeing them as the standard of high-quality goods or services. More specifically, consumers are willing to overpay for the labeled items, which implies that the requirements of sustainable production are completely met (Laroche, 2001). Therefore, when the consumers choose the eco-friendly products, the adverse impacts to the environment generated during production and consumption will be minimized. In other words, using ecofriendly products (green consumption) will indirectly promote eco-friendly production (green production). This is de facto an effective solution to limit the risks of climate change. Although, realizing green consumption and green production is a bit far-reached since it depends heavily on the self-consciousness and the financial situation of the consumers as well as of the producers. Hence, in order to promote green consumption and green production, specific regulations on the responsibilities of not only the State but also organizations, individuals in general and enterprises in particular during the production of eco-friendly goods; incentives on financial aid, land and sales support, and product promotion need to be immediately enacted. In reality, many Asian developing countries have already added these regulations into the environmental law. As a result, the number of consumers willing to overpay for eco-friendly products recently has shown that the markets for eco-friendly products are expanding (Tsakiridou, 2008).

(v) The development and application of technologies that help respond to climate change. Among all the methods and solutions to deal with climate change, developing and applying technologies is considered one of the best ways that generates positive results. In fact, these activities not only solve issues related to the reduction of emission but also play an indispensable role in proper exploitation and uses of natural resources, especially renewable ones. This is the key to form adaptation and mitigation of climate change. With that approach and the adjustments on developing and applying technologies to respond to climate change, environmental law needs to be renewed in order to regulate issues related to many activities, aiming to tackle multiple different problems such as: to develop branches and interdisciplinarity of science on management, assessment, supervising and forecasting the impacts of climate change on socio-economic development, environment, and community health; to investigate, research basic applied science, develop and transfer the modern technologies in greenhouse gas mitigation, to adapt to climate change; to enhance the competitiveness of key economic sectors, manufacturing, and to develop a low-carbon economy and green growth, etc.

\section{Conclusion}

With the adverse effects on human life and the natural environment, climate change has become an urgent global issue and, to respond to it, aside from international cooperation, countries need to strive for implementing many different solutions at once, including promoting the role of environmental law system. Depending on the status and conditions of each country, the 
environmental law system will be built and operated in accordance with the peculiarities of the natural and socio-economic conditions of that country. However, in order to efficiently promote the role of environmental law in responding to climate change, correctly identifying the requirements and basic issues that need to be adjusted by law is highly important. Some suggestions are:

- Integrating the content of responding to climate change into the strategies and plans for socio-economic development.

- Managing greenhouse gas emission and harmful components to the ozone layers.

- Developing renewable energy sources and retrieving energy from wastes.

- Producing and consuming eco-friendly products.

- Developing and applying technologies to respond to climate change.

Those are the most basic and vital points in dealing with climate change. If regulated specifically, they will create a consistent and firm legal corridor for the future activities to adapt and mitigate climate change. 


\section{References:}

United Nations Framework Convention on Climate Change (1992)

Fahim Hossain. (2021). Adaptation measures (AMs) and mitigation policies (MPs) to climate change and sustainable blue economy: a global perspective

Journal of Water and Climate Change 12 (5): 1344-1369. https://doi.org/10.2166/wcc.2020.152 The Vietnamese Association for Conservation of Nature and Environment (VACNE) (2009). Important notes to know about climate change. Science and Technics Publishing House. European Commission (EC). (2015). LIFE and Climate Change Adaptation. P.71 See https://ec.europa.eu/clima/sites/clima/files/docs/life_climate_change_adaptation_en.pdf Nguyen Duc Ngu. (2008) Climate change. Science and Technics Publishing House.

Walter Leal Filho, Jelena Barbir, Richard Preziosi (2010), Handbook of Climate Change and Biodiversity. Springer International Publishing Vo Quy. (2009) Climate change and biodiversity in Vietnam. Newsletter of Vietnam National University, Hanoi.

Canadian Institute of Actuaries. (2015) Climate Change and Resource Sustainability An Overview for Actuaries, Research Paper. P. 15. See: https://www.cia-ica.ca/docs/defaultsource/2015/215068e.pdf

Vietnam (2014). Law on Environmental Protection

Hanoi Law University (HLU). (2015). Textbook of Theory of the State and Law, People's Public Security Publishing House.

Nguyen Minh Doan. (2008). The role of law in the social life. The National Political Publishing House. P. $34-38$

Hanoi Law University (HLU) (2016). Textbook of Environmental Law. People's Public Security Publishing House. P. 32

Vu Thi Duyen Thuy (2016) Adjusting the law on the development of environmental industry in Vietnam - Needs and orientations, Democracy and Law Magazine

Joep Spiertz. (1997) The Role of Law in Natural Resource Management, Wilfrid Laurier University Press

Margaretha Wewerinke-Singh, 2019, State Responsibility, Climate Change and Human Rights under International Law, Hart Publishing, p.60 - 69

Edmond A. Mathez và Jason E. Smerdon. (2018). Climate Change: The Science of Global Warming and Our Energy Future. Columbia University Press.

World Bioenergy Association (WBA) (2020). Global Bioenergy Statistics. Stockholm, Sweden. p.9

Hoyyen Chan, Kamaruzzaman Sopian. (2018) Renewable Energy in Developing Countries, Local Development and Techno-Economic Aspects. Springer International Publishing. Laroche, M., Bergeron, J., Barbaro-Forleo (2001). Targeting Consumers Who are Willing to Pay More for Environmentally Friendly Products, Journal of Consumer Marketing. P. 503 Tsakiridou, E., Boutsouki, C., Zotos, Y., Mattas. (2008). Attitudes and Behaviour towards Organic Products: An Exploratory Study. International Journal of Retail \& Distribution Management 36/2, p.158 